УДК 634.10

DOI 10.30679/2219-5335-2020-6-66-15-27

ОСОБЕННОСТИ ВЕГЕТАЦИИ ИНТРОДУЦИРОВАННЫХ СОРТОВ ЯБЛОНИ

В УСЛОВИЯХ ЮГО-ВОСТОЧНЫХ ПРЕДГОРИЙ ДАГЕСТАНА

Казиев Магомед-Расул Абдусаламович д-р с.-х. наук

главный научный сотрудник

отдела агроландшафтного

земледелия

Шахмирзоев Руслан Абузарович

канд. биол. наук

ведущий научный сотрудник

отдела плодоовощеводства

и виноградарства

Караев Марат Караевич

д-р с.-х. наук

главный научный сотрудник

отдела плодоовощеводства

и виноградарства

Федеральное государственное научное бюджетное учреждение «Федеральный аграрный научный иентр Республики Дагестан», Махачкала, Дагестан

В статье показана сложность геоморфологических условий территории Республики Дагестан, обусловливающая необходимость решения вопросов научно обоснованного размещения садоводства с учетом вертикальной зональности.

В условиях юго-восточной предгорной подпровинции проведены наблюдения и выявлены закономерности прохождения основных фенологических фаз развития перспективных сортов яблони отечественной и зарубежной селекции. По результатам фенологических наблюдений, установлены средние даты наступления
UDC 634.10

DOI 10.30679/2219-5335-2020-6-66-15-27

\section{FEATURES OF VEGETATION OF INTRODUCED \\ APPLE TREE VARIETIES \\ IN THE SOUTH-EASTERN FOOTHILLS OF DAGHESTAN}

Kaziev Magomed-Rasul Abdusalamovich Dr. Sci. Agr.

Chief Research Associate

of Agricultural Landscape Agriculture

Department

Shakhmirzoev Ruslan Abuzarovich

Cand. Biol. Sci.

Leading Research Associate of Fruit and Vegetable growing and Viticulture Department

Karaev Marat Karaevich

Dr. Sci. Agr., Professor

Chief Scientific Research Associate of Fruit and Vegetable growing and Viticulture Department

Federal State

Scientific Budget Institution

«Federal Agricultural Research

Center of the Republic of Daghestan»,

Makhachkala, Daghestan

The article shows the complexity of the geomorphological conditions of the territory of the Republic of Daghestan, which makes it necessary to solve the issues of science-based placement of horticulture, taking into account vertical zoning. In the conditions of the South-Eastern foothill subprovinction, observations were made, and regularities of the main phenological phases of development of promising apple varieties of domestic and foreign selection were revealed. According to the results of phenological observations, the average dates of the onset of the main development phases 
основных фаз развития. Наблюдаемые стрессовые факторы среды, независящие от сорта, включены в учет при выведении средних показателей за ряд лет, так как они отражают биологические особенности сорта в определенных почвенно-климатических условиях. Проведена группировка сортов яблони по срокам началом цветения. Первая группа сортов - с ранним начало цветения 14-17 апреля (Маджести, Женева), вторая группа - 18-20 апреля (Кармен, Цивт-11) и третья группа со сроком цветения 22-24 апреля (Либерти, Айдаред, Фуджи, Голден Делишес, Чемпион Рено). Установлено, что в условиях юго-восточной предгорной провинции Дагестана средняя дата наступления вегетации сортов яблони наступает к концу второй декады марта. Сроки прохождение фенофаз в значительной степени зависит от сортовых особенностей. Проведенными фенологическими наблюдениями установлено, что длительность вегетации зависит от биологии сорта. В среднем, за годы изучения самый короткий срок вегетационного периода установлен у интродуцированного сорта Цивт 11 221 дней, а наиболее продолжительный у сорта Либерти - 239 дней, у сортов Женева, Маджести, Кармен, Айдаред, Чемпион Рено, Фуджи, Голден Делищес продолжительность вегетационного периода от 231 до 237 дней. В среднем по всем сортам она составила 233 дня.

Ключевые слова: ФЕНОЛОГИЯ, ЯБЛОНЯ, СОРТ, ИНТРОДУКЦИЯ, НАЧАЛО ВЕГЕТАЦИИ, ЦВЕТЕНИЕ, КЛИМАТИЧЕСКИЕ УСЛОВИЯ, ТЕМПЕРАТУРНЫЙ РЕЖИМ are established. The observed environmental stress factors that do not depend on the variety are included in the average indicators calculation for a number of years, since they reflect the biological characteristics of the variety in certain soil and climatic conditions. Apple varieties were grouped by the dates of the beginning of the blossom vegetation. The first group of varieties has an early start of blossoming on April 14-17 (Majesti, Geneva), the second group - April 18-20 (Carmen, Civt-11) and the third group has a blossom period of April 22-24 (Liberty, Idored, Fujii, Golden Delicious, Champion Reno).

It is established that in the conditions of the South-Eastern foothill province of Daghestan, the average date of vegetation for apple varieties occurs in the end of the second decade of March. The passage of the terms of phenophases largely depends on the varietal characteristics. Phenological observations have shown that the duration of vegetation of apple varieties depends on the biological characteristics.

On average, during the years of observation, the shortest vegetation period was found in the introduced variety of Civt11 221 days, and the longest - in the variety of Liberty - 239 days, in the varieties of Geneva, Majesti, Carmen, Idored, Champion Reno, Fujii, Golden Delisches the duration of the growing period was from 231 up to 237 days. The average duration of the growing season for all apple varieties was 233 days.

Key words: PHENOLOGY, APPLE-TREE, VARIETY, INTRODUCTION, BEGINNING OF VEGETATION, BLOSSOM PERIOD, CLIMATE CONDITIONS, TEMPERATURE REGIME

Введение. Для повышения урожайности плодовых насаждений и улучшения качества продукции важное значение имеет улучшение сортимента плодовых культур [1-6]. Изучение влияния условий внешней среды 
Плодоводство и виноградарство Юга России № 66(6), 2020 г.

на растительные организмы, раскрытие и познание закономерностей взаимоотношений живого организма с окружающей средой, является одной из главных задач фенологии [8-10].

Сложность орографических условий территории Дагестана, воздействие Каспийского моря и прилегающих к нему пустынных равнин создают большое разнообразие климатических условий республики. Средняя высота территории республики над уровнем моря составляет около 2100, максимальная - 4451 м, минимальная - ниже уровня моря на 28 м. Температурный режим Дагестана связана с высотой местности и формой рельефа.

Изучение возможностей адаптации различных сортов плодовых культур к условиям республики является актуальной задачей $[11,12]$.

Фенологические наблюдения - один из наиболее доступных и эффективных методов изучения особенностей развития растений в определенных экологических условиях, который позволяет установить сроки их вегетации, продолжительность отдельных фенофаз, устойчивость и продуктивность. Определение ритмов развития растений и продолжительность их нахождения той или иной фенофазе имеет очень большое значение для диагностики и отбора наиболее приспособленных сортов [13, 14].

Большинство авторов отмечают, что наступление фенологических фаз и длительность их прохождения различны по годам и зависят в большей степени от биологического потенциала и особенностей сорта, высоты над уровнем моря, почвенно-климатических условий местности и применяемой агротехники [15-20]. Даты наступления основных фенологических фаз вегетации изменяются по годам, но определенная последовательность вступления сортов в данную фазу до некоторой степени сохраняется.

Большинство интродуцированных сортов в регионе, проявляют недостаточную адаптивность. Изучение сроков прохождения фенологических фаз плодовых культур с учетом почвенно-климатических условий позволяет 
Плодоводство и виноградарство Юга России № 66(6), 2020 г.

определить реакцию сортов яблони на условия произрастания. Знание фенологии сортов необходимо при планировании сроков различных агромероприятий и имеет большое научно-производственное значение.

Объекты и методы исследований. Методологические подходы к оценке биологического потенциала сортов яблони представляют собой совокупность взаимоувязанных, последовательных действий, базирующихся на принципах и способах всесторонней оценки защитно-приспособительных возможностей многолетних растений.

Объектом исследований являются 9 интродуцированных сортов яблони (табл. 1).

Таблица 1- Характеристика сортов яблони

\begin{tabular}{|l|l|}
\hline \multicolumn{1}{|c|}{ Сорт } & \multicolumn{1}{|c|}{ Характеристика } \\
\hline Женева & $\begin{array}{l}\text { Выведен американскими селекционерами, летнего срока со- } \\
\text { зревания. В Госреестр внесен 2017 году и рекомендован к вы- } \\
\text { ращиванию в ЦЧЗ. }\end{array}$ \\
\hline Либерти & $\begin{array}{l}\text { Создан в результате скрещивания сортов Макинтош и Уэлси. } \\
\text { Сорт позднего срока созревания. В Госреестр включен } \\
2000 \text { году. }\end{array}$ \\
\hline Кармен & $\begin{array}{l}\text { Осенний сорт, создан в СКЗНИИСиВ совместно с с } \\
\text { ВНИИСПК, от скрещивания сортов Прима и Уэлси тетрапло- } \\
\text { идного. Сорт находится в Госреестре селекционных достиже- } \\
\text { ний, допущенных к использованию по Северо-Кавказскому } \\
\text { региону с 2014 года. }\end{array}$ \\
\hline Айдоред & $\begin{array}{l}\text { Сорт яблони позднезимнего срока созревания, выведен аме- } \\
\text { риканскими селекционерами в 1935 году на основе скрещи- } \\
\text { вания сортов Джонотан и Вагнер. }\end{array}$ \\
\hline Фуджи & $\begin{array}{l}\text { Зимний сорт японского происхождения, получен скрещива- } \\
\text { нием Ред Делищес и Рале Жанет в конце 1930 годов. }\end{array}$ \\
\hline Чемпион рено & $\begin{array}{l}\text { Раннезимний сорт чешской селекции, выведен в 1970 году в } \\
\text { процессе гибридизации сортов Голден Делищес и Ренет } \\
\text { оранжевый Кокса }\end{array}$ \\
\hline Голден Делищес & $\begin{array}{l}\text { Американский сорт зимнего срока созревания, получивший } \\
\text { широкое распространение. }\end{array}$ \\
\hline Маджести & Итальянский сорт раннего срока созревания. \\
\hline Цивт 11 & Итальянский сорт осеннего срока созревания. \\
\hline
\end{tabular}

Исследования проводились на опытно-экспериментальной базе ФБГНУ «ФАНЦ РД» в условиях предгорной провинции. Плодовые насаждения 2017 года закладки, схема посадки 5х2 м, подвой СК-2, высота над 
уровнем моря 477 м. Учеты и наблюдения проводились согласно общепринятой методике «Программа сортоизучения плодовых, ягодных и орехоплодных культур, 1999» [21].

Обсуждение результатов. Климат в районе проведения исследований (С.Стальский район, Республика Дагестан) умеренно континентальный, засушливый. По многолетним данным, среднегодовая температура воздуха составляет $12.3-13,0{ }^{\circ} \mathrm{C}$. Наиболее жаркими месяцами являются июль, август, абсолютный максимум температур $37-39^{\circ} \mathrm{C}$, абсолютный минимум $-8,9 \ldots-13.7^{\circ} \mathrm{C}$. Продолжительность безморозного периода в среднем составляет 289 дней. Зима с частыми, порой продолжительными оттепелями. Снежный покров не устойчив. Лето жаркое, сухое. Территория характеризуется как достаточно обеспеченная теплом для выращивания плодовых культур, сумма активных температур воздуха составляет $3429-3496{ }^{\circ} \mathrm{C}$.

Почвенный покров опытного участка представлен лугово-каштановыми почвами. Мощность горизонта А+B составляет 30-40 см, с содержанием гумуса до 2,0-2.9 \%, обеспеченность почвы подвижным фосфором (1,8-2,0 мг) и гидролиозуемым азотом (3,8-4,8 мг) средняя, обменным калием высокая - 40-55 мг на 100 г почвы. Агрофизические и агрохимические свойства почвы благоприятны для ведения культуры яблони.

Юго-восточная предгорная подпровинция имеет большие перспективы развития промышленного садоводства $[11,12]$. В то же время необходимо отметить наблюдаемое в последнее время усиление воздействия на растения абиотических и биотических стрессоров, способствующих резкому снижению продуктивности и качества плодов. К ним можно отнести усиление природно-климатических и фитосанитарных рисков производства плодов: засухи (1998, 2009, 2010, 2012, 2018 гг.), заморозков (2012 г.), развитие особо опасных вредителей и болезней: яблоневая тля, заболоник плодовый, щитовка; парша, альтернариоз, монилиоз и др. 
Плодоводство и виноградарство Юга России № 66(6), 2020 г.

Данные среднемесячной температуры воздуха и осадков в районе проведения исследований представлены таблицах 2, 3 .

Таблица 2 - Среднемесячная температура воздуха, ${ }^{\circ} \mathrm{C}$

(метеостанция «Касумкент»)

\begin{tabular}{|c|c|c|c|c|c|c|c|c|c|c|c|c|c|}
\hline \multirow{2}{*}{ Год } & \multicolumn{12}{|c|}{ Месяц } & \multirow{2}{*}{ За год } \\
\hline & I & II & III & IV & $\mathrm{V}$ & VI & VII & VIII & IX & $\mathrm{X}$ & XI & XII & \\
\hline 2017 & 0.3 & -0.3 & 5.3 & 10.3 & 16.2 & 19.3 & 24.4 & 25.1 & 20.3 & 11.3 & 7.0 & 3.5 & 11.9 \\
\hline 2018 & 0.2 & 2.6 & 5.8 & 10.7 & 18.3 & 21.8 & 26.2 & 22.1 & 19.1 & 13.8 & 6.3 & 2.9 & 12.5 \\
\hline 2019 & 2.4 & 1.5 & 5.0 & 9.9 & 17.7 & 24.0 & 23.5 & 22.9 & 16.9 & 14.0 & 6.1 & 3.7 & 12.3 \\
\hline Среднее & 0,9 & 1.2 & 5.3 & 10.3 & 17.4 & 21.7 & 24.7 & 23.4 & 18.7 & 13.1 & 6.4 & 3.4 & 12.2 \\
\hline
\end{tabular}

Таблица 3 - Среднемесячное количество осадков, мм (метеостанция «Касумкент»)

\begin{tabular}{|c|c|c|c|c|c|c|c|c|c|c|c|c|c|}
\hline \multirow{2}{*}{ Год } & \multicolumn{10}{|c|}{ Месяц } & \multirow{2}{*}{ За год } \\
\cline { 2 - 14 } & I & II & III & IV & V & VI & VII & VIII & IX & X & XI & ХII & \\
\hline 2017 & 22 & 35 & 10 & 36 & 47 & 79 & 27 & 6 & 31 & 27 & 34 & 12 & 366 \\
\hline 2018 & 24 & 35 & 45 & 46 & 27 & 22 & 30 & 82 & 6 & 7 & 30 & 18 & 372 \\
\hline 2019 & 7 & 12 & 45 & 34 & 53 & 22 & 38 & 4 & 52 & 6 & 35 & 8 & 316 \\
\hline Среднее & 17 & 27 & 33 & 39 & 42 & 41 & 32 & 31 & 30 & 13 & 33 & 13 & 351 \\
\hline
\end{tabular}

В условиях юго-восточной предгорной провинции Республики Дагестан для сортов яблони различного эколого-генетического происхождения были определены сроки выхода из периода покоя. Для выхода растений яблони из состояния вынужденного покоя и активизации ростовых процессов необходима сумма эффективных температур выше $30{ }^{\circ} \mathrm{C}$.

По итогам фенологических наблюдений рассчитана средняя многолетняя дата наступления фаз вегетации, проведена группировка сортов яблони по срокам созревания: ранние, средние и поздние. Даты прохождения основных фенологических фаз изучаемых сортов яблони приведены в таблице 4. 
Плодоводство и виноградарство Юга России № 66(6), 2020 г.

Таблица 4 - Даты прохождения фенологических фаз развития сортов яблони (среднее 2017-2019 гг.)

\begin{tabular}{|c|c|c|c|c|c|c|c|c|c|c|}
\hline \multirow[b]{3}{*}{ Сорт } & \multicolumn{9}{|c|}{ Средняя фенологическая дата } & \multirow{3}{*}{ 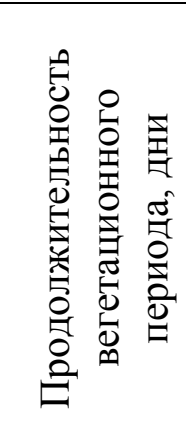 } \\
\hline & \multirow{2}{*}{ 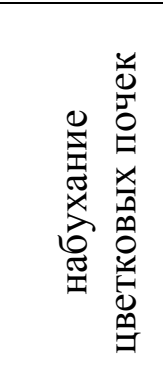 } & \multirow{2}{*}{ 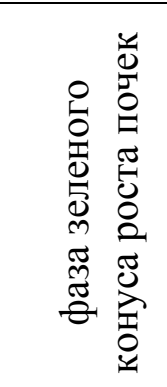 } & \multirow{2}{*}{ 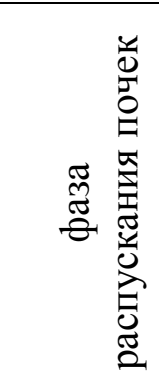 } & \multicolumn{4}{|c|}{ Цветение } & \multirow{2}{*}{ 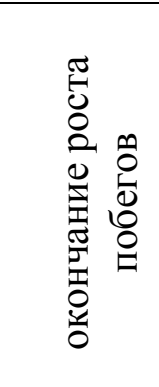 } & \multirow[b]{2}{*}{ 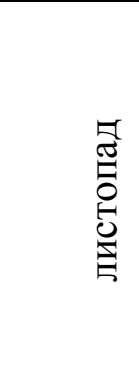 } & \\
\hline & & & & 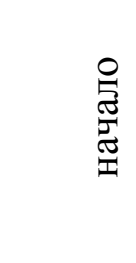 & $\begin{array}{l}\text { च्, } \\
\text { : } \\
\text { : }\end{array}$ & 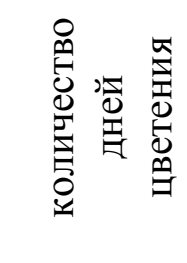 & 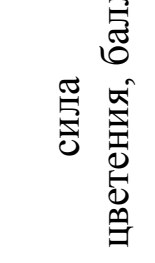 & & & \\
\hline Женева & 10.03 & 14.03 & 11.04 & 17.04 & 06.05 & 18 & 5.0 & 12.07 & 05.11 & 236 \\
\hline Маджести & 11.03 & 16.03 & 09.04 & 14.04 & 01.05 & 18 & 5.0 & 10.07 & 03.11 & 236 \\
\hline Либерти & 26.03 & 29.03 & 11.04 & 23.04 & 30.04 & 7 & 3.5 & 30.06 & 15.11 & 239 \\
\hline Цивт 11 & 24.03 & 28.03 & 10.04 & 20.04 & 01.05 & 10 & 3.5 & 03.07 & 06.11 & 221 \\
\hline Кармен & 18.03 & 23.03 & 08.04 & 18.04 & 30.04 & 12 & 4.5 & 16.07 & 15.11 & 237 \\
\hline Айдаред & 20.03 & 23.03 & 12.04 & 24.04 & 05.05 & 11 & 5.0 & 16.07 & 16.11 & 237 \\
\hline Фуджи & 20.03 & 25.03 & 12.04 & 24.04 & 04.05 & 10 & 3.0 & 15.07 & 20.11 & 236 \\
\hline $\begin{array}{l}\text { Голден } \\
\text { Делищес }\end{array}$ & 20.03 & 23.03 & 10.04 & 22.04 & 30.04 & 8 & 3.4 & 15.07 & 20.11 & 231 \\
\hline $\begin{array}{l}\text { Чемпион } \\
\text { рено }\end{array}$ & 27.03 & 30.03 & 11.04 & 22.04 & 02.05 & 10 & 4.0 & 20.07 & 12.11 & 236 \\
\hline $\begin{array}{l}\text { Среднее } \\
\text { по сортам }\end{array}$ & 20.03 & 23.03 & 10.04 & 22.04 & 03.05 & 11 & 4.2 & 10.07 & 12.11 & 233 \\
\hline
\end{tabular}




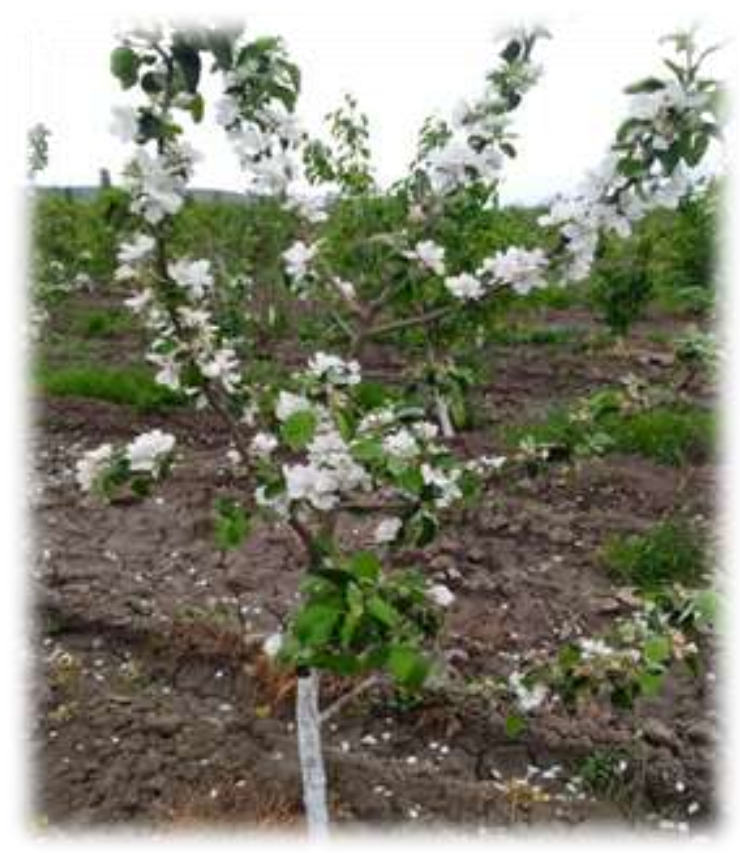

Рис. Цветение сорта яблони Женева

К сортам, начинающим вегетировать в ранние сроки, относятся: Женева (рис.), Маджести; в средние сроки - Кармен, Айдаред, Фуджи, Голден Делишес. Довольно поздно распускаются цветковые почки у сортов Либерти, Цивт 11, Чемпион Рено.

Установлено, что в условиях юго-восточной предгорной провинции Дагестана средняя дата наступления вегетации по всем сортам яблони наступает к концу второй декады марта. Прохождение сроков фенофаз в значительной степени зависит от сортовых особенностей. Период цветения плодовых культур в предгорной провинции отличается неустойчивостью погодных условий (в нашем случае весенние возвратные заморозки, туманы и дожди). Поздний срок цветения - ценная биологическая особенность сортов в условиях предгорной зоны.

По результатам исследований, определены сроки и продолжительность цветения интродуцированных сортов яблони. Наиболее раннее цветение отмечено у сортов Маджести и Женева (14-17.04), позднее - у сортов Айдаред, Либерти и Фуджи (22-24.04). Наибольшая разница в сроках начала цветения в зависимости от сорта составила 10 дней. Средняя дата начала цветения по всем изучаемым сортам приходится на 22 апреля. 
Плодоводство и виноградарство Юга России № 66(6), 2020 г.

Согласно полученным данным, сила цветения изученных сортов яблони варьировала от 3 до 5 баллов. Обильное цветение отмечено у сортов Женева, Маджести Айдаред и Кармен, среднее - у сортов Фуджи, Голден Делишес, Цивт-11 и Либерти. Продолжительность прохождения цветения сортов яблони составила от 7 до 18 дней (см. табл. 4).

Как известно, на сроки начала цветения яблони огромное влияние оказывает температурный режим, переход среднесуточной температуры через $5^{\text {C. }}$ В условиях юго-восточной предгорной провинции Дагестана, по многолетним данным, устойчиво этот период наступает во второй половине апреля. Сроки начала цветения в однотипных экологических условиях заметно меняются в зависимости от температуры воздуха. Чем она выше, тем раньше наступает цветение.

Сумма эффективных температур (переход среднесуточных температур через $+5{ }^{\circ} \mathrm{C}$ ) к началу цветения в среднем составила $140-160{ }^{\circ} \mathrm{C}$, количество дней от начала вегетации до цветения в зависимости от сорта 32-37 дней (см. табл. 4). Среднесуточная температура воздуха в период цветения составила $13-17{ }^{\circ} \mathrm{C}$, что соответствует оптимальным параметрам условий для прохождения фенофазы (табл. 5).

Таблица 5 - Сроки начала цветения сортов яблони и значения суммы эффективных температур

\begin{tabular}{|c|c|c|c|c|c|c|c|c|c|}
\hline \multirow[b]{2}{*}{ Показатель } & \multicolumn{9}{|c|}{ Copт } \\
\hline & 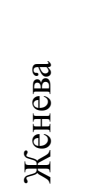 & 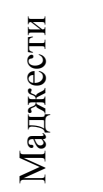 & 葛 & 吉 & 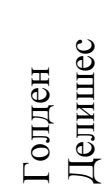 & 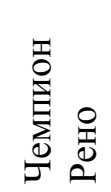 & $\begin{array}{l}5 \\
5 \\
8 \\
0 \\
\vdots \\
5 \\
5\end{array}$ & 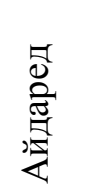 & 离 \\
\hline Начало цветения & 17.04 & 14.04 & 18.04 & 20.04 & 22.04 & 22.04 & 23.04 & 24.04 & 24.04 \\
\hline $\begin{array}{c}\text { Количество дней } \\
\text { от начала вегетации } \\
\text { до цветения }\end{array}$ & 32 & 32 & 36 & 35 & 35 & 37 & 37 & 37 & 36 \\
\hline $\begin{array}{c}\text { Сумма } \\
\text { эффективных } \\
\text { температур, }{ }^{\circ} \mathrm{C}\end{array}$ & 140,5 & 138,5 & 144,2 & 144,2 & 153,3 & 148,0 & 148,0 & 156,6 & 161,0 \\
\hline
\end{tabular}


Плодоводство и виноградарство Юга России № 66(6), 2020 г.

У изучаемых сортов яблони фенологическая фаза конец роста побегов наступает в период от 30 июня (Либерти) по 20 июля (Чемпион Рено). Окончание вегетации (листопад) является важной биологической особенностью в цикле развития яблони и в высокой степени определяет приспособленность сорта к данному климату и подготовленность к зимнему периоду. Листопад проходит при понижении температуры воздуха ниже $10-12{ }^{\circ} \mathrm{C}$ и уменьшении светового времени дня, а также при наличии появления слабых ранних заморозков.

Сроки окончания вегетации различных сортов яблони в значительной степени зависят от сортовых особенностей и условий произрастания. В связи с этим длительность вегетационного периода имеет важное значение и дает возможность определить приспособленность сорта к условиям территории. Сорт способен реализовать все имеющиеся возможности в полной мере только в том случае, если факторы внешней среды, воздействующие на растение, наиболее благоприятны для прохождения вегетационного периода. Сорта с коротким периодом вегетации успевают лучше подготовиться к предстоящим условиям перезимовки, с хорошо вызревшими побегами.

Проведенные фенологические наблюдения показали, что длительность вегетации сортов яблони зависит от биологических особенностей. Самый короткий вегетационный период установлен у интродуцированного сорта Цивт 11 - 221 дней, а наиболее продолжительный - у сорта Либерти - 239 дней, у сортов Женева, Маджести, Кармен, Айдоред, Чемпион Рено, Фуджи, Голден Делищес продолжительность вегетационного периода составила от 231 до 237 дней. В среднем по все сортам продолжительность вегетационного периода составила 233 дня. Сокращение длины вегетационного периода в отдельные годы происходит из-за позднего распускания почек или из-за ранних осенних заморозков и вследствие этого наступления вынужденного листопада. 
Bbывоb. Исследование прохождения фенологических фаз роста и развития сортов яблони различных эколого-географических групп позволило выяснить степень приспособленности их к экологическим условиям Дагестана, установить сроки начала и продолжительности основных фенофаз в зависимости от метеорологических факторов и биологических особенностей сортов и выявить требования сортов к температурному режиму.

Изученные сорта показывают высокую адаптивность в условиях юговосточных предгорий Дагестана, что определяет перспективу их использования в интенсивных насаждениях.

По результатам проведенных наблюдений выделены сорта - с ранним сроком начала вегетации: Маджеста, Женева;

- со средним: Кармен, Айдаред, Фуджи, Голден Делишес;

- с поздним: Либерти, Чемпион Рено, Цивт11.

В условиях юго-восточной предгорной подпровинции Дагестана продолжительность цветения яблони по всем изученным сортам колебалась от 7 до 17 дней. В зависимости от сорта продолжительность вегетационного периода составляла 221-239 дней.

\section{Литература}

1. Драгавцев А.П., Трусевич Г.В. Южное плодоводство. М.: Колос. 1970. 493 с.

2. Ефимова И.Л., Богданович Т.В. Сравнительная оценка яблони в коллекции СКЗНИИСиВ для совершенствования зонального сортимента // Субтропическое и декоративное садоводство: сборник научных трудов ФГБНУ ВНИИЦиСК. Сочи: ФГНУ ВНИИЦиСК, 2015. Вып. 53. С. 36-40.

3. Кандаурова Е.Ф. Биологические особенности интродуцированных сортов яблони в Молдавии: автореф. дис. ... канд. с-х. наук / Кандаурова Екатерина Федоровна. Кишинев, 1972. 28 с.

4. Матвеева Р.Н., Буторова О.Ф., Моксина Н.В. Селекция яблони в Ботаническом саду им. Крутовского. Красноярск: Изд-во СбГТУ, 2006. 357 с.

5. Buttner, R. Yenebank work for preservation of the genetic diversity of apple / R. Buttner, M. Fischer, P.L. Forsline, M. Yeibel, V.V. Ponomorenko. - Acta Hort, 2000. № 538. - P. 39-42.

6. Mohan, J.S. Breeding Platation Free Crop: Temperate Species / J.S. Mohan, P.M. Priyadarshan // Springer Sciense+Business Media, LLS. - 2009. - 294 p. 
7. Кешелашвили Ш.А. Итоги изучения фенологических фаз в сортах яблони в условиях горной зоны Душетского района // Труды Груз. СХИ. Тбилиси, 1986. С. 57-63.

8. Минин А.А. Опыт и перспективы фенологических наблюдений // Фенологические методы в научных исследованиях и школе: материалы региональной науч-практ. конф., посвященной 100-летию со дня рождения В.А. Батманова (Екатеринбург, 16.12.2000). Екатеринбург, 2001. С. 22-24.

9. Садыгов А.Н. Фенология сортов яблони селекции Аз.НИИ садоводства и субтропических культур в агроклиматических условиях Куба-Хачмаской зоны // Аграрный научный журнал. 2014. № 8. С. 38-40.

10. Селянинов Г.Т. Климатическое обоснование специализации сельскохозяйственных культур по районам // Растениеводство СССР. Л.,1930. С. 567-570.

11. Велибекова Л.А. Перспективы размещения промышленного садоводства Дагестана // Садоводство и виноградарство. № 2. 2019. С .33-39.

12. Мурсалов М.М-К., Насрутдинов У.И., Загиров Н.Г. Вертикальная зональность и адаптивно-ландшафтное размещение плодовых культур на территории Дагестана. Махачкала, 2005. С. 63.

13. Нестеров Я.С. Ритм годичной жизнедеятельности яблони в зависимости от условий произрастания // Труды по прикладной ботанике, генетике и селекции. 1976. Т.57. Вып.1. С. 3-17.

14. Weiser, C.J. Cold resistance and injury in woody plants // Science. - 1970. - V. 169. - № 3952. - P. 1269-1277.

15. Griesdach, K. Leistung verechiedener Sorten-Unterlagen-Kombinationen unter den Standortbedingungen des Dresdntr und des Havellandischer Jbstanbaugebietes / K. Griesdach // Gartenbau. - 1979. - P. 143-145.

16. Mika, A. Growth and cropping of dwarf Jonagold (Jonica) apple trees at the density ramged from 2,000 to 10,000 per ha and trained as slender spindle, super spindle and v system / A. Mika, E. Piskor // Acta Hort. - 1997. - № 451. -P. 473-477.

17. Preston, A.P. The Behaviour of Fourteen Clonal Apple Rootstock in an Exposed Hilltop Orchard / A.P. Preston // Annual Rep. (East Malling Res. St.). - Kent, 1962. - P. 63-64.

18. Singh, L.B. Studies in biennial learing (II). - J. of Horticultural sci. - Vol.24. № 1,2. - 1948. - P. 45-65.

19. Weber, M.S. Optimizing the tree density in apple orchards on dwarf rootstocks / M.S. Weber //Acta Hort. - 2001. - № 557. - P. 229-234.

20. Werth, K. Qualitat ist auch im Obstbau Trumpi / K. Werth // Obstbau. - 1985. № 11. - P.488-491

21. Седов Е.Н., Огольцова Т.П. Программа и методика сортоизучения плодовых, ягодных, и орехоплодных культур. Орел,1999. 608 с.

\section{References}

1. Dragavcev A.P., Trusevich G.V. Yuzhnoe plodovodstvo. M.: Kolos.1970. 493 s.

2. Efimova I.L., Bogdanovich T.V. Sravnitel'naya ocenka yabloni v kollekcii SKZNIISiV dlya sovershenstvovaniya zonal'nogo sortimenta // Subtropicheskoe i dekorativnoe sadovodstvo: sbornik nauchnyh trudov FGBNU VNIICiSK. Sochi: FGNU VNIICiSK, 2015. Vyp. 53. S. 36-40.

3. Kandaurova E.F. Biologicheskie osobennosti introducirovannyh sortov yabloni v Moldavii: avtoref. dis. ... kand. s-h. nauk / Kandaurova Ekaterina Fedorovna. Kishinev, 1972. $28 \mathrm{~s}$.

4. Matveeva R.N., Butorova O.F., Moksina N.V. Selekciya yabloni v Botanicheskom sadu im. Krutovskogo. Krasnoyarsk: Izd-vo SbGTU, 2006. 357 s. 
5. Buttner, R. Yenebank work for preservation of the genetic diversity of apple / R. Buttner, M. Fischer, P.L. Forsline, M. Yeibel, V.V. Pono-morenko. - Acta Hort, 2000. № 538. - P. 39-42.

6. Mohan, J.S. Breeding Platation Free Crop: Temperate Species / J.S. Mohan, P.M. Priyadarshan // Springer Sciense+Business Media, LLS. - 2009. - 294 p.

7. Keshelashvili Sh.A. Itogi izucheniya fenologicheskih faz v sortah yabloni v usloviyah gornoj zony Dushetskogo rajona // Trudy Gruz. SHI. Tiblisi, 1986. S. 57-63.

8. Minin A.A. Opyt i perspektivy fenologicheskih nablyudenij // Fenologicheskie metody $\mathrm{v}$ nauchnyh issledovaniyah i shkole: materialy regional'noj nauch-prakt. konf., posvyashchennoj 100-letiyu so dnya rozhdeniya V.A. Batmanova (Ekaterinburg, 16.12.2000). Ekaterinburg, 2001. S. 22-24.

9. Sadygov A.N. Fenologiya sortov yabloni selekcii Az.NII sadovodstva i subtropicheskih kul'tur v agroklimaticheskih usloviyah Kuba-Hachmaskoj zony // Agrarnyj nauchnyj zhurnal. 2014. № 8. S. 38-40.

10. Selyaninov G.T. Klimaticheskoe obosnovanie specializacii sel'skohozyajstvennyh kul'tur po rajonam // Rastenievodstvo SSSR. L.,1930. S. 567-570.

11. Velibekova L.A. Perspektivy razmeshcheniya promyshlennogo sadovodstva Dagestana // Sadovodstvo i vinogradarstvo. № 2. 2019. S .33-39.

12. Mursalov M.M-K., Nasrutdinov U.I., Zagirov N.G. Verti-kal'naya zonal'nost' i adaptivno-landshaftnoe razmeshchenie plodovyh kul'tur na territorii Dagestana. Mahachkala, 2005. C. 63.

13. Nesterov Ya.S. Ritm godichnoj zhiznedeyatel'nosti yabloni v zavisimosti ot uslovij proizrastaniya // Trudy po prikladnoj botanike, genetike i selekcii. 1976. T.57. Vyp.1. S. 3-17.

14. Weiser, C.J. Cold resistance and injury in woody plants // Science. - 1970. V. 169. - № 3952. - P. 1269-1277.

15. Griesdach, K. Leistung verechiedener Sorten-Unterlagen-Kombinationen unter den Standortbedingungen des Dresdntr und des Havellandischer Jbstanbaugebietes / K. Griesdach // Gartenbau. - 1979. - R. 143-145.

16. Mika, A. Growth and cropping of dwarf Jonagold (Jonica) apple trees at the density ramged from 2,000 to 10,000 per ha and trained as slender spindle, super spindle and $\mathrm{v}$ system / A. Mika, E. Piskor // Acta Hort. - 1997. - № 451. -R. 473-477.

17. Preston, A.P. The Behaviour of Fourteen Clonal Apple Rootstock in an Exposed Hilltop Orchard / A.P. Preston // Annual Rep. (East Malling Res. St.). - Kent, 1962. - P. 63-64.

18. Singh, L.B. Studies in biennial learing (II). - J. of Horticultural sci. - Vol.24. - № 1,2. - 1948. - P. 45-65.

19. Weber, M.S. Optimizing the tree density in apple orchards on dwarf rootstocks / M.S. Weber //Acta Hort. - 2001. - № 557. - P. 229-234.

20. Werth, K. Qualitat ist auch im Obstbau Trumpi / K. Werth // Obstbau. - 1985. № 11. - R.488-491

21. Sedov E.N., Ogol'cova T.P. Programma i metodika sortoizucheniya plodovyh, yagodnyh, i orekhoplodnyh kul'tur. Orel, 1999. 608 s. 